\title{
MAGIA Y HUMOR EN UN RELATO DE ÁLVARO CUNQUEIRO
}

\author{
Marina MAYORAL \\ Universidad Complutense de Madrid
}

Uno de los rasgos característicos de las narraciones de Alvaro Cunqueiro es el uso especial que hace de los elementos fantásticos.

Lo más llamativo, lo que más ha sido comentado y hasta imitado ha sido su forma de reinterpretar la mitología o los relatos clásicos: la conversión del mago Merlín, del Ulises griego o de Simbad el marino en personajes del mundo galaico, perfectamente integrados en una sociedad diferente a aquella de la que proceden, pero sin perder su carácter mítico. La fantasía de Cunqueiro se desenvuelve con toda naturalidad en los temas de la materia de Bretaña o del mundo homérico: El rey Arturo, la reina Ginebra, Lanzarote del Lago son personajes a los que parece haber conocido tanto como a los que frecuentaban el local del Pallarego, el mindoniense barbero y músico que él convirtió en personaje de sus relatos. Las historias que cuentan los soldados y capitanes de la Guerra de Troya las sentimos tan cercanas como las que hablan de menciñeiros o de fuxidos.

Esa faceta de la recreación de temas clásicos es sin duda una de las grandes avenidas por las que circula la capacidad fabuladora del narrador, pero no es la única. En los cuentos de A. Cunqueiro, sobre todo en los que narra historias referidas al mundo galaico rural, nos encontramos con una elaboración peculiar de los elementos fantásticos.

En sus grandes obras, Un hombre que se parecía a Orestes, Las mocedades de Ulises, así como en los relatos del ciclo de Bretaña, el autor parte de una realidad ya mitificada, petrificada en cierto modo por la cultura, y en ellos la función de la fantasía cunqueiriana es vivificar, insuflar nueva sangre al mito, añadiendo 
detalles desconocidos que los humanizan y nos acercan a aquellos personajes del pasado; aunque también utiliza la técnica de romper los esquemas de lo que ya conocíamos, que es otra forma de acercarnos al mito, renovándolo.

En los cuentos referidos al mundo rural galaico la fantasía actúa en un doble sentido: por una parte tiende a transformar la realidad cotidiana elevándola a mito mediante la aparición de lo maravilloso, y por otro acerca el mundo de lo sobrenatural a la realidad de cada día, presentándolo como algo tan habitual que no precisa de explicaciones. El resultado es un universo en la que lo mítico y lo real, lo cotidiano y lo extraordinario, lo de este mundo y lo del otro se mezclan de tal forma que no pueden separarse '. Ese mundo, contado con humor, me parece a mí la creación más original de Alvaro Cunqueiro.

Vamos a ver alguno de los procedimientos utilizados por el autor en los relatos fantásticos de ambiente rural, analizando el cuento «La cabeza de Bouso», del libro de relatos La otra gente ${ }^{2}$, cuyas peripecias se sitúan en un espacio de fícción llamado Mondoñedo.

Como sucede en otros cuentos de Alvaro Cunqueiro, el narrador parte de un suceso que dice haber leído en un periódico. Esa noticia, que en otros casos es una referencia histórica, a veces auténtica y a veces inventada, tiene por función hacer pensar al lector que, aunque lo que va a leer le resulte raro, se trata de un hecho documentado. Así en «La cabeza de Bouso» el punto de partida es la noticia aparecida en el Time de Nueva York (el prestigio del periódico avala la credibilidad de la noticia) de que en Chicago operaron a un hombre para quitarle un hueso que le sobraba en la cabeza. Del paciente se puntualiza que era hijo de italianos y que el hueso superfluo, en forma de haba, lo tenía entre el frontal y un parietal, precisión fisiológica que contribuye también a aumentar la sensación de autenticidad de la noticia.

A continuación el autor asegura que eso mismo (lo de tener un hueso de más en la cabeza) ya le había ocurrido en Mondoñedo a un individuo del que se da el nombre: un tal Bouso de Prado. Se adelanta que no fue operado sino el que el hueso lo expulsó por la nariz. Y, una vez captada la atención del lector, pasa a contar la historia desde el principio.

El relato empieza en el terreno de un realismo casi costumbrista: Bouso discute en una feria con un forastero, valenciano por más señas, acerca de la calidad de la comida gallega, y en la discusión llegan a las manos. El valenciano lo zarandea y Bouso cae desmayado al suelo. Desde el momento en que el personaje

' Sobre la peculiar mezcla de elementos realistas y fantásticos pueden verse entre otros estudios el de Anxo Tarrío 1989, y el «Estudio preliminar» de Diego Martínez Torrón 1985.

${ }^{2}$ Las citas se hacen por la Antología de relatos cortos seleccionados por Anxo Tarrío 1991. 
recupera el sentido entramos en el terreno de lo fantástico: Bouso tiene sueltos los huesos de la cabeza.

Ese hecho imposible se presenta como un hecho real: Bouso oye como suenan sus huesos al mover la cabeza, y también los oyen sus vecinos; no se trata por tanto de una alucinación. Aceptado como real el hecho fantástico, se pasa a describir la situación, que es muy desagradable para el protagonista: alguno de los huesos sueltos se le viene con frecuencia hacia delante y le impide ver, lo cual, aparte de la molestia, implica para el afectado un riesgo de ceguera permanente. Sólo de modo transitorio, con una hábil sacudida, su mujer consigue a veces despejarle la vista.

Desde el realismo de la feria y las disputas localistas hemos pasado a un mundo similar al de la esquizofrenia paranoide: partiendo de un hecho falso se organiza toda una secuencia perfectamente lógica. Es la técnica de los episodios de los molinos de viento de El Quijote y del Informe sobre ciegos de Sábato el punto de partida es irreal (los molinos no son gigantes, ni los ciegos una sociedad criminal) pero a partir de ahí lo que sucede es congruente. Lo mismo sucede en el cuento de Cunqueiro: A nadie se le sueltan los huesos de la cabeza sin morirse, pero, una vez aceptado el hecho fabuloso de que Bouso tiene sueltos los huesos de la cabeza y está vivo, es lógico que los huesos sueltos le produzcan grandes molestias.

Para arreglar esa situación la pareja acude a un componedor, Primo de Baltar, y el remedio que este ofrece se mueve también en la lógica de lo fantástico: el menciñeiro le pone al enfermo en la parte trasera de la cabeza parches de cera caliente, con lo cual, «pasando el espíritu de la cera al interior, pegaba los huesos unos contra otros, y todos a lo que Primo llamaba 'la bóveda de la campana', que la hay en algunas cabezas».

En este momento se introduce en el relato un nuevo elemento fantástico: esa «bóveda de la campana», órgano excepcional que solo algunos individuos poseen. ¿Quiénes? A lo fantástico se une lo lírico en la respuesta: La tienen «los que soñando dormidos escuchan correr el viento». Respuesta ambigua y sugerente donde las haya pues no aclara nada y abre mil posibilidades misteriosas.

Cuando ya parece que estamos metidos de lleno en el terreno de lo fantástico, llegan unas escogidas precisiones que nos llevan de nuevo al mundo de la realidad más palpable: «Terminado el pegamento, Bouso y Primo comieron un cabrito y bebieron media cántara de vino. Primo cobró ciento veintisiete pesetas por la operación: las veintisiete pesetas eran de la cera virgen gastada. Bouso puso el cabrito, el vino, un queso, el pan, los cafés y el coñac. También le regaló a Primo una corbata con el retrato de Machado, que se la mandara un sobrino que vivía en La Habana». 
Los detalles costumbristas de la comida: cabrito, queso, pan y vino, y el detalle histórico de la corbata con la efigie del presidente cubano Gerardo Machado nos sitúan de nuevo en el plano de una realidad gallega rural, de campesinos y emigrados en la que, sin embargo, lo extraordinario pasa a ser cotidiano. Así vemos a la mujer de Bouso poniéndole cada sábado a su marido un parche de cera caliente en la cabeza para mantener los hueso bien pegados.

Pese a los cuidados de la mujer, uno de los huesos se le suelta. Aunque no lo ven, por el sonido y por el modo de desplazarse se dan cuenta de que es alargado y redondo como un cigarrillo. $Y$ el hueso empieza a dar la lata: «Bouso estaba podando distraído y sentía venir el hueso desde atrás y golpearle en la frente: ¡Tac!».

Vuelven al componedor, que les dice que ese hueso le sobra, provocando un gran desconcierto en el protagonista: «¿Cómo va a sobrarme un hueso? -se admiraba Bouso»».

Esa admiración del personaje es un ejemplo de maestría narrativa. Se asombra de que le sobre un hueso, y no de todo lo que le ha ocurrido antes: que se le suelten los huesos de la cabeza y que no se muera; que se los peguen con parche de cera caliente, que uno se le despegue y se dedique a pasearse por el interior de su cráneo...

El asombro del protagonista centra la atención del lector sobre lo que se pretende presentar como hecho excepcional, que fue, recordemos, el punto de partida: que a un hombre lo operaron en Chicago para quitarle un hueso que le sobraba.

La explicación que da el menciñeiro en respuesta al asombro del personaje universaliza los hechos puntuales narrados, tanto la noticia del Times como la historia de Bouso de Prado: Algunas personas tienen un hueso, llamado hueso del azogue, que les sobra y que conviene eliminar.

Bouso no necesitó de operación como el americano: Primo de Baltar le preparó unos polvos de rapé y al tercer estornudo salió por la nariz el hueso, blanquito y muy limpio, como de ala de pollo.

El hueso lo enterraron porque dijo el menciñeiro que los huesos de azogue en ciertas épocas son contagiosos y no fuese a haber epidemia.

Todo esto, sin duda, no lo sabían los cirujanos de Chicago que extrajeron el hueso sobrante de la cabeza del hijo de los italianos. Esa sabiduría es exclusiva del mundo en el que se mueven Primo de Baltar y Bouso: es propia de un grupo escogido, como la ciencia de los antiguos sacerdotes egipcios o la magia de Merlín; algo arcano, al que muy pocos tienen acceso, absolutamente cerrado para la civilización de los grandes rascacielos. 
Sin necesidad de operación, Bouso quedó curado. La única secuela que le dejó su mal fue que le pesaba la cabeza, en la parte de atrás. Cosa natural, nos dice el narrador, ya que tiene allí pegados los huesos todos.

Ese comentario final, que sentimos irónico, subraya la inseparable unión de lo realista y lo fantástico. Estamos en un mundo en el que las fronteras entre realidad y fantasía se diluyen, en el que la realidad más prosaica y cotidiana se teje con los hilos de lo mágico y lo maravilloso. Pero en la que el humor marca la distancia entre el narrador y los hechos narrados. Ese humor es la marca del autor.

Frente al aséptico suceso del que da cuenta el Times (una simple anomalía físiológica que se resuelve con una operación), el relato de Álvaro Cunqueiro nos introduce en una realidad compleja en la que el misterio y la fantasía son parte fundamental, pero también lo es el humor con que ese mundo está visto. Y eso es lo que lo diferencia los cuentos de tema gallego de Álvaro Cunqueiro tanto del relato fantástico como del costumbrista. El autor nos introduce en un mundo en el que los hechos extraordinarios ocurren con absoluta naturalidad. Un mundo mágico, regido por su propia lógica interna, y por unos saberes y poderes ancestrales. Nos hace asomarnos a ese mundo y sonrie: ustedes podrán no creer en las meigas, pero haberlas, hailas. 


\section{BIBLIOGRAFÍA}

CUNQUEIRo, Álvaro, 1991. La historia del caballero Rafael, Antología de relatos cortos. Selección de Anxo Tarrío, Barcelona, Edhasa, colección Relatos.

MARTínEZ TORRÓN, Diego, 1985. Estudio preliminar de Las mocedades de Ulises, Madrid, Espasa-Calpe, col. Austral.

TARrí, Anxo, 1989. Alvaro Cunqueiro ou os disfraces da melancolía, Vigo, Galaxia, colección Agra aberta. 